\title{
O MAL COMO PRIVAÇÃO ${ }^{1}$
}

\author{
Selma Aparecida BASSOLI ${ }^{2}$
}

- RESUMO: O presente artigo procura mostrar como Kant utiliza o conceito matemático de grandeza negativa para caracterizar o mal como privação e como este será, posteriormente, a base do seu conceito de mal radical.

- PALAVRAS-CHAVE: mal, falta, privação, Kant.

Em uma nota do seu texto de 1793, A religião dentro dos limites da simples razão, Kant aponta duas maneiras diferentes de tratar o mal em oposição ao bem (KANT, 3, nota 5, p. 275). A primeira é considerar o mal como uma simples carência de um fundamento do bem; a segunda é conceber o mal como um fundamento positivo, contrário ao bem.

No primeiro caso, o mal é entendido como ausência de ser, assim como uma sombra pode ser compreendida como ausência de luz. Neste caso, o mal caracteriza-se pela simples ausência de uma razão positiva para a sua existência, ou seja, é algo que não tem consistência em si mesmo, é a mera conseqüência da falta de um motivo moral.

No segundo caso, o mal possui um fundamento positivo de determinação em oposição a um outro, igualmente positivo. Neste outro contexto, uma sombra passa a ser compreendida de forma diferente, ou seja, como resultado de um obstáculo que se opõe à passagem da luz, e o mal passa a ser

1 Artigo recebido em 07/2005; aprovado para publicação em 08/2005.

2 Mestranda do Departamento de Filosofia da UNICAMP; sbassoli@terra.com.br 
concebido como conseqüência de uma determinação do arbítrio em realidade contrária ao motivo moral. Neste segundo caso, o mal é um princípio ativo; adquire um caráter positivo, que difere da neutralidade do primeiro.

O meu objetivo será mostrar que o texto pré-crítico de Kant, Ensaio para introduzir em filosofia o conceito de grandeza negativa, de 1763, é um importante recurso para a compreensão da diferença entre estes dois tipos de mal.

No prefácio a este ensaio, Kant afirma que há dois procedimentos possíveis quando se deseja aplicar os conhecimentos da matemática à filosofia. Por um lado, a imitação do método, que ele considera inútil e prejudicial; por outro lado, o uso filosófico de certos ensinamentos matemáticos. Tendo em vista este segundo modo, Kant propõe a utilização do conceito matemático de grandeza negativa, aplicando-o tanto às questões do mundo físico quanto às do plano moral.

A grandeza negativa não é a simples negação de uma grandeza, mas alguma coisa positiva que é oposta a uma outra, também positiva. Esta oposição entre grandezas positivas não é aquela considerada do ponto de vista lógico, considerada como noção abstrata, mas um tipo de oposição efetiva, que pode ser verificada nos fenômenos do mundo. A negatividade positiva desta grandeza é obtida através de um tipo específico de oposição. Portanto, a chave para a compreensão do significado de uma grandeza negativa, e da diferença entre os tipos de mal mencionados por Kant, é a distinção entre a oposição lógica e a oposição real.

A oposição lógica é uma oposição por contradição que consiste em afirmar e negar, ao mesmo tempo, alguma coisa a respeito de um mesmo sujeito. Como exemplo, podemos dizer que um corpo em movimento é alguma coisa; assim como um corpo que não está em movimento é também alguma coisa; mas um corpo que, sob a mesma relação, estivesse ao mesmo tempo em movimento e em repouso, seria algo impossível, ou um nada considerado de forma absoluta.

De maneira diferente da oposição lógica, a oposição real situa opostos sem contradição, dois predicados de uma mesma coisa. Na oposição real, uma tendência suprime, total ou parcialmente, o efeito da outra, sendo que as duas tendências são verdadeiros predicados de um único corpo e se relacionam ao mesmo tempo. A conseqüência pode ser igualmente nada, mas este terá um sentido diferente daquele da contradição. Como exemplo, podemos mencionar a força motriz atuando em um corpo em determinado sentido e um esforço igual para mover este corpo no sentido contrário. Estas forças são possíveis ao mesmo tempo como predicados em um mesmo corpo. A conseqüência desse embate é um estado de equilíbrio entre essas forças, que pode ser representado pelo zero, caracterizando o repouso. Entretanto, este zero não é o nada absoluto; pois esta neutralidade tem apenas o sentido de estabilidade e equilíbrio. 
Tanto na oposição lógica, quanto na oposição real, o efeito pode ser o nada, porém este terá um sentido diferente em cada um desses dois tipos de oposição. O nada da contradição lógica não pode ser representado e leva a uma ausência ou impossibilidade de pensamento. Já o nada da oposição real não leva a uma contradição e ele pode ser facilmente representado através da contraposição de grandezas às quais atribuímos valores negativos e afirmativos. Convencionalmente, numa oposição real, podemos caracterizar uma das grandezas através do sinal (-) e a outra através do sinal (+). Mas é importante esclarecer que a grandeza qualificada como negativa é real e simplesmente oposta àquela considerada como positiva. Isto significa que as duas grandezas envolvidas na oposição real são positivas. Os sinais atribuídos a cada uma das grandezas não indicam categorias especiais de objetos que seriam positivos ou negativos. Eles indicam apenas a relação entre eles. Os sinais contrários atribuídos às duas grandezas indicam apenas que ambas são positivas, mas estão numa relação de oposição.

Kant propõe as seguintes regras fundamentais para a caracterização de uma oposição real (Cf. KANT, 1, p. 85):

1) As determinações opostas umas às outras devem estar situadas em um mesmo sujeito. Pois, supondo que uma determinação se encontre em uma coisa e uma outra determinação, não importa qual, se encontre em uma outra coisa, não haverá nenhuma oposição verdadeira.

2) É impossível que uma das determinações opostas, em uma oposição real, seja o contraditório da outra; neste caso, o conflito seria de ordem lógica e impossível.

3) Uma determinação não pode negar senão o que foi apresentado pela outra determinação.

4) As determinações, na medida em que elas se opõem reciprocamente, não podem ser ambas negativas. Os dois predicados devem ser positivos, mas de modo que, quando ligados no mesmo sujeito, a conseqüência de um predicado suprima a conseqüência do outro.

Através da distinção entre oposição lógica e oposição real, Kant distingue dois modos de negação: a falta e a privação. A consideração da negação como privação resulta da oposição real entre dois fundamentos que se anulam mutuamente; a negação como falta resulta da oposição lógica de acordo com o princípio de contradição. Kant, no texto sobre as grandezas negativas, afirma:

Chamarei privação (privatio) a negação conseqüência de uma oposição real; toda negação não resultante deste tipo de incompatibilidade deve aqui ter o nome de falta (defectus, absentia). A última não pede um princípio positivo, mas simplesmente a falta de um princípio positivo; quanto à primeira, ela possui um verdadeiro 
princípio de posição e um princípio igual que lhe é oposto. O repouso é, em um corpo, ou simplesmente uma falta, quer dizer, uma negação do movimento por ausência de força motriz; ou uma privação, na medida em que existe uma força motriz, mas o movimento conseqüente é destruído por uma força oposta. (KANT, 1, p. 88) ${ }^{3}$

Buscando explicitar a diferença entre estes modos de negação, Kant se detém sobre a questão de saber se o desprazer pode ser considerado somente uma falta de prazer ou, então, um princípio de privação do prazer. No primeiro caso, teríamos apenas o objeto contraditório do prazer; no segundo, alguma coisa positiva em si.

Para esclarecer esta distinção, Kant menciona a situação vivida por uma mãe que recebe a notícia de que seu filho combateu heroicamente por sua pátria. Devido a esta informação, um sentimento de prazer invade o seu coração. Em seguida, porém, ela recebe um outro comunicado, através do qual fica sabendo que seu filho morreu em combate. Segundo Kant, esta última informação diminui consideravelmente o prazer que essa mãe havia sentido inicialmente, o que nos leva a compreender que "o desprazer não é simplesmente uma falta de prazer, mas o motivo positivo da supressão, total ou parcial, do prazer, que resulta de um outro princípio" (KANT, 1, p. 92). Esta positividade faz com que o desprazer seja considerado um prazer negativo.

De forma diferente, "a falta de prazer, assim como o desprazer, na medida em que ele deriva da ausência de princípios, chama-se indiferença (indifferentia)" (KANT, 1, p. 88). A negação por falta não exige um fundamento positivo de determinação, mas se caracteriza exatamente pela ausência de qualquer fundamento. Neste caso, temos que entender que algo não é pela simples ausência de uma razão positiva para a sua existência. Dizemos neste sentido: este ser não está vivo porque lhe falta a vida; ou este ser está vivo porque lhe falta a morte. Entretanto, Kant acredita que, do ponto de vista de uma negação por falta, não é possível explicarmos "como o que existe, cessa de ser" (KANT, 1, p. 102). Pois, para que haja uma explicação, é necessário que seja estabelecida a causa ou a razão que faz desaparecer ou aniquilar uma coisa existente. Kant cita o seguinte exemplo:

A representação do sol, engendrada pela força da minha imaginação, ocupa meu espírito neste momento. No instante seguinte, eu paro de pensar neste objeto. A representação, que era minha, desaparece do meu espírito, e o estado o mais próximo do precedente é a negação. Se me contentar em esclarecer, como explicação, que o pensamento cessou de ser pela razão que no instante seguinte eu parei de produzi-lo, a resposta não difere de modo algum da questão; pois nos importa precisa-

3 Todas as traduções deste texto, aqui constantes, foram feitas a partir da tradução francesa e são de minha responsabilidade. 
mente aqui conhecer como uma ação que tem realmente lugar pode ser interrompida, quer dizer, cessar de ser. (KANT, 1, p. 102)

Na medida em que nos restringimos a pensar que a representação deixou de ser simplesmente porque deixou de ser produzida, Kant afirma que não há avanço algum. Porquanto não há exatamente uma explicação, no sentido em que não estabelecemos nenhuma causa para o desaparecimento da representação do Sol. A resposta se baseia apenas na constatação da interrupção da existência de algo que, por esta via, permanece sem solução. Se quisermos avançar, propõe Kant, é necessário que se pense o deixar de ser, ou seja, a interrupção da existência, em termos de uma oposição real, através da negação por privação, que estabelece um fundamento positivo como a causa da supressão, parcial ou total, das coisas que existem no mundo.

Devemos, portanto, procurar pela causa ou fundamento positivo de oposição, em toda explicação sobre algo que deixou de existir. Pois o conhecimento sobre a destruição de algo, assim como sobre a sua geração, necessita de uma causa real para o seu estabelecimento.

Partindo da negação como privação, Kant afirma que podemos entender a aversão como um desejo negativo, o ódio como um amor negativo, a fealdade como uma beleza negativa e o mal como um bem negativo. Kant distingue, neste ensaio de 1763, dois tipos de males: por falta (mala defectus) e por privação (mala privationis). O primeiro é uma negação na qual nenhum princípio funda uma posição oposta; o segundo supõe uma razão positiva para suprimir o bem, sendo, portanto, um bem negativo. Esta segunda espécie de mal é considerada pior que a primeira, porque não dar algo a quem necessita deve ser considerado um mal; ${ }^{4}$ mas extorquir e roubar são, em relação ao necessitado, males ainda maiores, pois eqüivalem a um dar negativo (KANT, 1, p. 92).

A filosofia prática pode, segundo Kant, fazer um uso fecundo do conceito de oposição real. O demérito, entendido através deste modo de oposição, não é meramente a falta de uma virtude, mas uma virtude negativa

4 Inicialmente, Kant sugere a omissão como um possível exemplo de mal por falta; mas, prosseguindo com sua argumentação sobre esses dois tipos de males, faz uma observação importante: não dar já é uma privação, quando este ato viola a consciência de que devemos prestar ajuda ao próximo. Assim haveria, no exemplo mencionado, apenas uma diferença de grau relacionado à privação, que faz com que extorquir seja pior que omitir ajuda. Ambos os casos seriam exemplos de dar negativo. Não dar algo a quem necessita (omissão) não pode ser considerado, portanto, um bom exemplo de mal por falta, e só poderá valer nos casos em que a omissão não ocorrer em virtude de uma oposição à consciência de que devemos prestar ajuda a quem dela necessita. Um exemplo que poderia expressar melhor a omissão por falta, no contexto kantiano, seria aquele do indivíduo que não ajuda o próximo unicamente porque desconhece que ele está precisando de ajuda. 
(meritum negativum). "O demérito surge em função da existência, em um ser, de uma lei interior (seja simplesmente a consciência, seja a consciência de uma lei positiva) que ele infringe" (KANT, 1, p.94). O demérito não é, portanto, uma ausência de mérito que não nos é imputável, mas é uma determinação consciente que se opõe à lei, pela qual somos responsáveis.

A idéia de virtude negativa, concebida através do modelo de oposição real, ressurge em 1793, quando Kant trata do conceito de mal radical. O esquema geral do seu texto pré-crítico é retomado em uma nota presente no texto A religião dentro dos limites da simples razão (KANT, 3, nota 5, p. 275), quando Kant assume uma posição rigorista em termos morais. O rigorismo admite que o homem seja, por natureza, ou moralmente bom ou moralmente mau. Este posicionamento descarta a visão, baseada na experiência, segundo a qual o homem é, ao mesmo tempo, bom e mau, ou melhor, haveria um meio-termo moral sustentado pelo fato de que o homem é bom, em algumas partes, e mau em outras.

O rigorismo kantiano concebe que entre uma boa e uma má intenção (princípio interno das máximas) não há meio-termo. Então, sendo dada a lei moral em nós, a falta de acordo do arbítrio com esta lei só é possível como conseqüência de uma determinação em realidade contrária ao motivo moral. Esta determinação "negativa", conseqüência de uma oposição real, caracteriza o mal moral que pertence ao arbítrio dos seres humanos. O mal como falta caracteriza as ações dos animais e também nos permite entender como a idéia de dever não pertence à vontade dos seres puramente racionais.

Os animais são seres destituídos de razão. De modo que não podemos julgá-los moralmente, visto que o critério para um julgamento moral, que exige a conformidade do arbítrio com relação à lei moral, não se aplica a eles. Se os animais não possuem razão, não possuem também o fundamento do bem representado pela lei moral e, portanto, não têm acesso ao que a lei ordena. Segundo Kant,

Um animal carente de razão não pratica nenhuma virtude; mas esta omissão não constitui um demérito (demeritum), pois não houve nenhuma infração a uma lei interior, e o zero, ou a omissão, não foi determinado em conseqüência de uma oposição à lei moral, ou pela ação de um contrapeso. Ela não é aqui uma privação, mas uma negação por falta de razão positiva. (KANT, 1, p. 94)

Uma outra situação em que podemos pensar o mal como contradição, vale dizer, como resultante de uma negação por falta, é aquela que se refere aos seres puramente racionais. Neles, o fundamento do bem está presente, porém não como lei do dever que o arbítrio pode ou não acolher, mas como determinação única da vontade. Para os seres puramente racionais há ne- 
cessariamente uma harmonia do arbítrio com a lei, o que exclui qualquer noção de obrigação associada à vontade, a qual está sempre em conformidade com a lei moral. De acordo com Kant,

Se a razão determina infalivelmente a vontade, as ações de um tal ser, que são conhecidas como objetivamente necessárias, são também subjetivamente necessárias, isto é, a vontade é a faculdade de escolher só aquilo que a razão, independentemente da inclinação, reconhece como praticamente necessário, quer dizer, como bom. (KANT, 2, p. 123, grifo do autor)

Desse modo, para os seres providos unicamente de razão, a deliberação é única e perfeitamente de acordo com a lei moral, sendo necessariamente boa.

Nos casos considerados até agora, cada ser é carente de um dos dois termos presentes na natureza humana: a razão no caso dos animais; a sensibilidade no caso dos seres puramente racionais. No caso dos homens, temos que pensar o mal como um fundamento positivo de oposição à lei moral, ou seja, o mal como privação. Pois, além de serem dotados de razão, os homens têm uma natureza sensível que os predispõe a desejos e inclinações, o que vincula a determinação do seu arbítrio a um imperativo moral .

O homem tem essencialmente dois móveis de determinação do seu arbítrio: o primeiro é a lei moral, proveniente de sua razão; o segundo são as inclinações da sensibilidade. Tomados em si mesmos, os dois móveis não permitem um julgamento moral, uma vez que o mal não pode estar em nenhum deles por si mesmo. A possibilidade do mal está apenas na forma da relação entre estes dois móveis.

Se tentarmos entender a forma desta relação a partir do modelo de oposição real, temos que considerar estas duas motivações como forças realmente existentes e que se contrapõem de algumas maneiras. A primeira dessas forças seria a disposição originária para o bem; a segunda seria a propensão natural para o mal. Ao concebermos a relação entre esta disposição para o bem e esta propensão para o mal, através do modelo de oposição real, podemos dizer que ocorre, no arbítrio, um conflito inevitável entre duas forças reais e sempre presentes para o homem. Isto significa que nem a força do bem, nem a força do mal, opostas entre si, podem ser eliminadas da consideração do arbítrio, pois Kant considera impossível para o homem extirpar a consideração da própria lei e negar a obrigação pura para com ela, ao mesmo tempo em que a propensão para o mal é atribuída a todos os homens, até aos melhores, o que significa que o mal está entrelaçado à natureza humana.

Entretanto, há uma peculiaridade no modo como estas forças se contrapõem no arbítrio, pois bem e mal não têm o mesmo estatuto originário. 
O bem é fruto da razão humana e da liberdade que dela advém; ele é preeminente e somente a ele é atribuído o caráter originário. Já o mal por privação é adquirido, e "precisa do bem para ser, em sua positividade, o nãoser que ele é" (ROSENFIELD, p.59). Assim, a vontade que quer o mal opõese à lei moral, contudo ainda mantém o reconhecimento por esta lei, assim como um assassino que, apesar do seu crime, considera válida a lei que ele transgrediu.

A propensão para o mal consiste no "fundamento subjetivo da possibilidade de desviar-se das máximas da lei moral" (KANT, 3, p. 279). Pode também ser entendida como a incapacidade do homem de aceitar a lei moral como motivo único de determinação do seu arbítrio. Kant distingue três diferentes graus nesta propensão: o primeiro é a debilidade do coração humano na observância das máximas adotadas, também chamada de fragilidade da natureza humana. De acordo com este grau de propensão, a força do motivo moral, que atua de modo insuperável na idéia, é vencida pela força dos motivos da sensibilidade na determinação do arbítrio. Há uma boa intenção, mas que não é forte o suficiente, sendo que o arbítrio é efetivamente determinado pelas inclinações; mesmo assim, o modo de pensar não fica corrompido. Um exemplo seria aquele indivíduo que, diante do dever de dizer a verdade, e tendo a intenção de dizê-la, não é capaz ou não tem a coragem necessária para isso.

O segundo grau é a inclinação para misturar móbiles imorais com os morais. É também chamado de impureza do coração humano. Conforme este grau de propensão, o motivo que atua na determinação do arbítrio não é puramente moral, ou seja, o homem possui boa intenção e procura agir sob as máximas do bem. Porém a lei moral não atua como motivo suficiente, sendo necessária a atuação das forças da inclinação no mesmo sentido da motivação moral, para que o homem consiga determinar seu arbítrio consoante aquilo que o dever exige, a saber, as suas ações são conformes ao dever, mas não são realizadas por puro dever. Neste caso, o dever de dizer a verdade é cumprido quanto à sua matéria, ou seja, o indivíduo não mente; mas a sua motivação não é puramente moral porque ele diz a verdade motivado, por exemplo, pelo medo de ser punido, ou então pela crença de que será recompensado por isso.

O terceiro e máximo grau desta propensão para o mal é a inclinação do arbítrio para máximas que põem os motivos da lei moral depois de outros motivos não morais; é chamada de malignidade ou perversidade do coração humano, porque inverte a ordem moral dos motivos no arbítrio. De acordo com ele, a maneira de pensar, no que se refere à intenção moral, está corrompida em sua raiz e, mesmo que dela resultem ações conformes ao dever, o homem será julgado como moralmente mau. Este terceiro grau de propensão se manifesta quando um homem, apesar de reconhecer o que a lei orde- 
na, quer uma exceção para ela. Como exemplo, temos o indivíduo que defende um suposto direito de mentir, quando a verdade põe a vida de alguém em risco. Deste modo, ele subordina a lei moral a um outro motivo, considerando, de algum modo, que sua transgressão é moralmente justificável.

Vemos, portanto, que a diferença essencial entre estes graus de propensão para o mal está em que, no primeiro e no segundo graus, o modo de pensar não é corrompido, mas no terceiro, no que se refere à intenção moral, o modo de pensar fica essencialmente pervertido. Porém, para Kant, este modo de pensar que se perverte não tem sua origem na razão, mas no coração, sendo portanto uma perversão que apenas confere ao homem um coração mau. Esta perversão do coração, visualizada através do modelo de oposição real, revelaria que a força das inclinações sensíveis pode subjugar a força da lei moral, todavia não chega a exterminá-la da consideração do arbítrio.

A perversão proveniente do coração estabelece um limite para a maldade que pode ser atribuída ao homem, que impede a afirmação de que o homem seja capaz de visar ao mal pelo mal. Este corresponderia àquilo que Kant denomina perversão da razão moralmente legisladora, que se refere a uma racionalidade que teria, na negação e na oposição à lei moral, o motivo do seu arbítrio, transformando a oposição à moralidade em fim em si mesmo. Esta seria a expressão de uma racionalidade diabólica, de uma malignidade extrema que, para Kant, é impossível na natureza humana.

A idéia de uma vontade absolutamente maligna estaria, nos termos de Kant, em oposição lógica à definição de homem como um ser portador de racionalidade e liberdade intrínsecas. A corrupção da razão teria que ser concebida a partir da idéia de liberdade, entendida como obediência incondicional ao imperativo da moralidade, porém aliada à indiferença com relação à lei moral, o que a torna contraditória.

Entretanto, se Kant considera impossível atribuir malignidade ao homem, isto não é devido a uma limitação do modelo de oposição real, utilizado inicialmente por ele para tratar da questão do mal. Pois a malignidade concebida como um fundamento positivo que nega a lei moral é uma expressão genuína de uma grandeza negativa e resulta desse tipo de oposição. Mas concebida dessa forma, a malignidade alcança um estatuto originário que a torna equiparável ao bem, de forma que um sujeito poderia ser ou moralmente bom ou moralmente maligno. Entretanto, um sujeito do qual se poderia predicar a malignidade não seria, para Kant, um homem, mas um ente diabólico.

Recusando a possibilidade de conferir esse predicado ao homem, Kant abandona o modelo de oposição real, e a partir de uma recusa por contradição, elimina um desdobramento da noção de mal radical por considerá-lo incompatível com seu sistema. Desse modo, o fundamento subjetivo que se 
opõe à lei moral não chega a destruir o fundamento objetivo da moralidade, mantendo intacta a lei que representa o bem, assim como uma certa concepção de natureza humana que a sustenta.

BASSOLI, S.A. Evil as privation. Trans/Form/Ação, (São Paulo), v.28 (2), 2005, p.95104.

- ABSTRACT: This paper attempts to show how Kant makes use of the mathematical concept of negative magnitude in order to characterize evil as privation and how the latter may be later considered the basis of his concept of radical evil.

- KEYWORDS: evil, lack, privation, Kant.

\section{Referências bibliográficas}

KANT, I. Essai pour introduire en philosophie le concept de grandeur négative. Traduction: Roger Kempf. Paris: J. Vrin, 1949.

Fundamentação da metafísica dos costumes. Tradução: Paulo Quintela. São Paulo: Abril Cultural (Coleção Os Pensadores), 1980.

A religião dentro dos limites da simples razão. Tradução: Tânia Maria Bernkopf. São Paulo: Abril Cultural (Coleção Os pensadores), 1980.

ROSENFIELD, D.L. Do mal: para introduzir em filosofia o conceito de mal. Tradução: Marco A. Zingano. Porto Alegre: L\&PM Editores 1988. 